\title{
O Estágio Curricular como Desenvolvimento Profissional na Perspectiva dos Alunos de Hotelaria
}

\author{
The Curricular Training as Professional Development from the Perspective of \\ Hospitality Students
}

La Pasantía como Desarrollo Profesional en la Perspectiva de los Estudiantes de Hostelería

\author{
Daniela Gouveia Viana $^{1}$ \\ Luiz Octávio de Lima Camargo ${ }^{2}$
}

\begin{abstract}
Resumo
Como os alunos de hotelaria avaliam os processos de treinamento e desenvolvimento dirigidos a si mesmos enquanto estagiários e na comparação com os processos direcionados aos funcionários das organizações hoteleiras? Para dar conta deste problema, lançou-se mão de referencial teórico dos campos da administração e da hotelaria. Metodologicamente, optouse pela técnica qualitativa da análise de conteúdo de entrevistas semi-estruturadas, dentro das seguintes categorias: eventual experiência profissional anterior ao estágio; amplitude da função do estagiário de hotelaria dentro do hotel; programas de treinamento nos hotéis (para os funcionários; para os estagiários); tipologia de treinamentos aplicáveis ao estágio; interesse do aluno-estagiário pelo estágio. Os resultados mostraram que há evidências de um mal estar dos alunos com relação à atividade. De início, extremamente motivados, ansiosos por conhecer e desenvolver uma prática profissional, que se promete agradável, marcada pelo contato com os clientes e cheia de surpresas e de acontecimentos agradáveis, não raro alguns se frustram. No mais das vezes, tratados como mão de obra barata, submetidos a tarefas subalternas para as quais são designados nunca por suas qualidades técnicas, o desgaste e a decepção são naturais.
\end{abstract}

Palavras-chave: hotelaria; treinamento; desenvolvimento organizacional; estágio curricular.

\footnotetext{
${ }^{1}$ Pós-graduanda em Hotelaria Hospitalar pelo Instituto Israelita de Ensino e Pesquisa Albert Einstein (2012) e Bacharel em Hotelaria pela Universidade Anhembi Morumbi (2011). Guest Relations, em hotel de médio porte, rede hoteleira nacional e categoria upscale/superior localizado em São Paulo (capital). E-mail: danigov1989@hotmail.com.

${ }^{2}$ Livre-docente pela USP/EACH. Doutor em Sciences de l'Education pela Univ.Sorbonne-Paris V (Rene Descartes) (1982), título revalidado pela FE-USP e graduado em Comunicações/Jornalismo pela ECA/USP (1974). Professor do Programa de Mestrado em Hospitalidade da Universidade Anhembi Morumbi e docente do bacharelado em Lazer e Turismo da EACH-USP. E-mail: octacam@uol.com.br.
} 


\begin{abstract}
How hospitality students evaluate the process of training and development directed at themselves, while trainees, and in comparison with other processes directed to hotel employees? To handle this problem, this article has employed the theoretical fields of administration and hospitality. Methodologically, we chose the technique of qualitative content analysis of semi-structured interviews, within the following categories: any professional experience prior to the stage, according to the amplitude of the trainee hotel within the hotel, training programs in hotels (for employees; for trainees), type of training applicable to the stage; interest of the trainee. The results showed that there is a certain unease of the students' activity. At first, highly-motivated, eager to meet and develop a professional practice, which promises pleasant, marked by the contact with customers and full of pleasant surprises and events, often some are frustrated. More often than not, treated as cheap labor, subjected to menial tasks for which they are never called by its technical qualities, the wear and disappointment are natural.
\end{abstract}

Keywords: hospitality; training; organizational development; curricular training.

\title{
Resumen
}

¿Cómo los estudiantes de hospitalidad evalúan los procesos de entrenamiento y desarrollo dirigidos a sí mismos mientras que aprendices y en la comparación con los procesos dirigidos a los empleados del hotel? Para manejar este problema, se emplean los campos teóricos de la administración y la hospitalidad. Metodológicamente, se optó por la técnica de análisis de contenido cualitativo de entrevistas semi-estructuradas en las siguientes categorias: la experiencia profesional anterior, tareas designadas a los aprendices, programas de formación en los hoteles (para los empleados, para los alumnos), el tipo de formación aplicable a la etapa, el interés del estudiante-becario de la pasantía. Los resultados mostraron que hay pruebas de un malestar de los estudiantes respecto a la actividad. Al principio, la motivación, ganas de conocer y desarrollar una práctica profesional, que promete agradables, marcado por el contacto con los clientes y lleno de agradables sorpresas y acontecimientos, algunos se sienten frustrados. Muy a menudo, tratados como mano de obra barata, sometidos a trabajos al azar y no por su técnica, el desgaste y la decepción son naturales.

Palabras clave: hospitalidad; rntrenamiento; desarrollo organizacional; Aprendices.

\section{Introdução}

$\mathrm{Na}$ área de turismo e hotelaria, conhece-se no país apenas uma publicação sobre estágios (BISSOLI, 2006), que trata dos procedimentos didático-pedagógicos necessários para o desenvolvimento da disciplina em Cursos Superiores de Turismo e Hotelaria. Seu enfoque é, 
pois, como deve ser conduzido o estágio, pouco se detendo a autora na forma como o mesmo se desenvolve. Passa ao largo, assim, como se verá adiante, do problema aqui abordado.

Em outras áreas de formação profissional, há estudos mais pertinentes. Espíndula et Alii (2007) analisando o caso dos estudantes de ciências contábeis da Universidade Federal de Uberlândia, concluem, ao final, que, segundo os alunos, " $80 \%$ dos estágios proporcionaram experiências úteis para o futuro profissional".

Já outros analistas estão atentos às mazelas do estágio. Segundo Osório e Schoenali (1999), analisando o caso dos estagiários do curso de Administração da Universidade Federal de Pernambuco, "estágio constitui, para as empresas, fonte de mão de obra barata e, para os estudantes, constitui fonte de renda." Afirmam, ainda, no mesmo texto:

A forma como o estágio é considerado pela maioria dos atores envolvidos em sua realização, mostra que existe urgente necessidade de novas abordagens, tanto por parte das unidades concedentes, como das instituições de ensino e, principalmente, dos próprios estagiários (1999, p.12).

Jasinski (1999) também reafirma que a contratação de estagiários é uma maneira de a empresa obter mão de obra qualificada, a baixo custo, sendo poucas as que proporcionam autonomia para o estagiário desenvolver todo o seu potencial. Roesch (2005), também analisando o estágio em cursos de Administração, afirma que, se é verdade que muitos alunos aproveitam o estágio para se desenvolver profissionalmente, para muitos outros as experiências adquiridas são insatisfatórias.

A legislação vê o estagiário como um aprendiz em serviço. Isso quer dizer que ele está ligado tanto ao processo de aprendizagem como ao processo produtivo, mas sem perder o foco principal no primeiro. Deduz-se da lei que o estagiário também necessita integrar-se à cultura da empresa, já que de outra forma ele se torna um corpo estranho e todos os objetivos do estágio se perdem. Mas como se passam as coisas no mundo real? Como as empresas traduzem essas noções para o âmbito destes alunos recrutados nas universidades com vistas a propiciar-lhes um primeiro contato com o mercado de trabalho? 
Conhecer o que se passa realmente com o estágio implica saber como esses dois atores (empresa e estagiário) se portam em serviço, ou melhor, de que forma o estágio não é um desconforto nem para um nem para outro.

Esta proposta é aqui objeto de vários recortes, a começar do problema que aqui é colocado nos seguintes termos:

- Como os alunos avaliam os processos de treinamento e desenvolvimento dirigidos a si mesmos, enquanto estagiários, e na comparação com os processos direcionados aos demais funcionários nas organizações?

Um segundo recorte diz respeito ao tipo de curso pesquisado, o de hotelaria. Destaque-se que esta questão surge num horizonte de previsões muito favoráveis para o mercado hoteleiro, devido aos principais acontecimentos da nova fase brasileira, com a Copa do Mundo de 2014 e o investimento que esse mega-evento esportivo proporcionará ao nosso país. Mas também desperta o fantasma da falta de mão de obra qualificada. O estágio deveria ser, pois, uma iniciativa auspiciosa para ambos os lados, para as empresas que podem aproveitar os estagiários mais competentes e para o estagiário que seria obrigado a conhecer melhor a estrutura de um hotel e preparar-se para a esperada escalada da oferta de empregos.

A maior dificuldade foi conseguir ex-estagiários disponíveis para a entrevista. Mesmo com a promessa de anonimato em relação ao nome e à IES à qual estavam vinculados, eles se negavam. A dificuldade em se obter uma amostra mais representativa do universo pesquisado redundou, certamente, numa limitação às conclusões deste artigo, mas, por outro lado, o desinteresse, a má-vontade e não raro, a hostilidade de alguns alunos em negarem-se à entrevista, certamente constituiu em si uma pista para os resultados obtidos por meio desta pesquisa. Assim, foram selecionados doze alunos concluintes do estágio curricular obrigatório que trabalharam em um ou mais setores dos hotéis (hospedagem, Alimentos e Bebidas e Eventos). Esses alunos foram selecionados randomicamente e, a pedido dos mesmos, mantendo-se em anonimato, sendo quatro estagiando em hotéis de categoria luxo e super luxo (upscale), quatro alunos, estagiários de hotelaria em hotéis de categoria turística e superior (midscale) e quatro alunos, estagiários de hotelaria em hotéis de categorias simples e econômica. 
Desenvolveu-se, assim, um estudo limitado a esclarecer a percepção dos estagiários de hotelaria em relação aos processos de treinamento e desenvolvimento nas empresas de serviços hoteleiros. Do ponto de vista metodológico, optou-se pela técnica qualitativa da análise de conteúdo de entrevistas semi-estruturadas, dentro dos seguintes passos: definição de categorias e indicadores de análise; definição do roteiro de entrevistas com base nas categorias e indicadores de análise; execução e transcrição das entrevistas; análise das entrevistas segundo as categorias escolhidas: eventual experiência profissional anterior ao estágio (como efetivo ou estagiário de hotelaria e/ou em áreas afins); importância da eventual experiência profissional anterior para a contratação como estagiário de hotelaria; amplitude da função do estagiário de hotelaria dentro do hotel (outras funções além de hospedagem, alimentos e bebidas e eventos); programas de treinamento nos hotéis (para os funcionários; para os estagiários); tipologia de treinamentos aplicáveis ao estágio (integração; crosstraining; site inspection; on-the-job, outros); interesse do aluno-estagiário pelo estágio (satisfação/insatisfação; motivação/desmotivação). Como a pesquisa o permitiu e dada sua natureza exploratória, em função das limitações da amostra, julgou-se oportuno entrevistar também dois gestores de hotéis, como contraponto ao depoimento dos alunos.

Esta reflexão seguirá o seguinte percurso. Partir-se-á das noções de treinamento e desenvolvimento, referenciais da atuação profissional em geral, inclusive de estagiários. Em seguida, passar-se-à à análise de cada categoria acima referida como objeto de um item especial.

\section{Treinamento e Desenvolvimento (T\&D)}

Os processos de treinamento e desenvolvimento (CHIAVENATO, 2010; BOOG, 2006; ROBBINS, 2009), recebem duas abordagens distintas: a tradicional e a moderna. A tradicional segue o modelo de treinar apenas quando surge alguma oportunidade ou necessidade, a partir de um esquema randômico, em que as pessoas são escolhidas aleatoriamente. A iniciativa é reativa, baseando-se na existência de um problema ou necessidade, em uma visão de curto prazo, aquilo que jocosamente foi traduzido como "gerenciamento por crise". Já a moderna segue um modelo planejado de treinamento das pessoas como parte de uma cultura organizacional, em um esquema intencional que integra a 
todos, em uma atitude proativa de antecipação de necessidades, em uma visão de longo prazo que visa o futuro, baseado no consenso das pessoas, em uma condição de instabilidade e mudança em que tudo deve mudar para melhor e visando ao provisório e mutável.

Assim sendo, o treinamento está mais ligado a operações técnicas e mecânicas, de motivação, enquanto que o desenvolvimento se refere mais amplamente aos conceitos educacionais e filosóficos. A noção de desenvolvimento preside assim à de treinamento (BOHLANDER, SNELL e SHERMAN, 2005). Enquanto o treinamento é projetado para as pessoas de nível não gerencial, embora possa também ser aplicado a todos os níveis ou setores da organização, o desenvolvimento objetiva, de início, pessoas de nível gerencial, sendo que, em sua estratégia de implantação, cabem treinamentos variados. Entre os dois processos, uma diferenciação evidente ocorre em relação à projeção do tempo ou à amplitude do espectro da empresa envolvido, ou seja, o treinamento é projetado para o curto prazo, em função de um propósito definido e específico, como a execução de uma determinada atividade, por exemplo, enquanto que o desenvolvimento envolve uma educação mais ampla para propósitos genéricos e de longo prazo.

Apesar dos objetivos distintos dos processos de treinamento e desenvolvimento, ambos, se utilizados conjuntamente, resultam em uma alternativa de educação profissional bem mais diligente. Até um passado não muito distante, alguns especialistas em recursos humanos consideravam o treinamento um instrumento para adequar cada empregado a seu cargo e desenvolver a força de trabalho da organização a partir do preenchimento de cargos. Modernamente, segundo Chiavenato (2010), o treinamento é considerado uma maneira de desenvolver competências nos indivíduos para que se tornem mais produtivos, criativos e inovadores, a fim de contribuir melhor para os objetivos organizacionais e se tornarem cada vez mais valiosos.

O treinamento, em um sentido mais amplo, é considerado um esforço dirigido no sentido de equipe, com o propósito de fazer a mesma atingir as metas da organização de modo mais parcimonioso possível. Por isso, o treinamento não deve ser entendido como uma despesa, mas sim como um investimento de extrema importância para a organização, cujo retorno é altamente compensador desde que focado em metas bem determinadas e que traga os resultados almejados. Assim sendo, o treinamento, segundo Chiavenato (2010), é uma fonte 
de lucratividade ao permitir que as pessoas contribuam efetivamente para os resultados do negócio, ao enriquecer o patrimônio humano através da formação do capital intelectual das organizações, pressupondo quatro etapas: transformar pessoas em talentos; transformar talentos em capital humano; transformar capital humano em capital intelectual e transformar capital intelectual em resultados tangíveis para a organização.

Desenvolvimento organizacional ainda se define por um esforço planejado e consciente de mudança organizacional que, para ocorrer, requer necessariamente uma mudança individual em termos de postura, atitude, comportamento, pensamento, conceitos, idéias, etc.

Essas reflexões iniciais, que valem para o conjunto de empregados, valem também para os estagiários, objeto deste artigo? Como as empresas traduzem essas noções para o âmbito destes alunos recrutados nas universidades com vistas a propiciar-lhes um primeiro contato com o mercado de trabalho?

\section{A Especificidade do T\&D na Hotelaria}

Segundo Aguiar (2008) e Freund (2005), as organizações hoteleiras apresentam muitas características das prestadoras de serviços, compartilhando com estas, muitos fatores, tais como, custos fixos altos, mão de obra intensiva, baixos salários e horário de trabalho especial. Contudo, de acordo com Mullins (2004); Hayes e Ninemeier (2005); Castelli (2005); Clarke e Chen, 2005), os hotéis guardam algumas especificidades: a produção e o consumo simultâneos (os serviços de hospedagem são criados e entregues na hora exata, justamente onde o cliente se encontra, ou seja, são criados e consumidos ao mesmo tempo; por exemplo, o atendimento do recepcionista ao cliente não pode ser estocado para uso futuro; $\underline{\text { a }}$ perecibilidade: os serviços não podem ser estocados e, se não forem utilizados, serão perdidos; por exemplo, muitas vezes, não há quartos disponíveis para suprir uma demanda mais alta do que a esperada, resultando em uma oportunidade perdida para a geração de receita extra, ou ainda, quando um apartamento fica vazio em um determinado dia, o hotel não pode mais recuperar a diária; por isso, devido ao consumo de hospedagem ser simultâneo à produção hoteleira, considera-se impossível a estocagem; a mão de obra intensiva: a prestação de serviços em organizações hoteleiras dá ênfase à importância da interação direta entre empregados e clientes, assim sendo, a mão de obra é recurso importante na 
determinação da eficiência organizacional; entretanto, a falta de qualificação das pessoas que trabalham na hotelaria é uma dura realidade, sentida não apenas pelos dirigentes hoteleiros, mas também e principalmente pelos hóspedes, pela falta de qualidade dos serviços; $\underline{a}$ intangibilidade: os serviços de hospedagem possuem algo que não se pode tocar ou sentir, que são os fatores intangíveis: a decoração, o clima acolhedor, do "sentir-se em casa", a assistência recebida, a cortesia revelada em cada gesto, o sorriso de um funcionário da equipe, etc.; a padronização: os procedimentos adotados no preparo de um apartamento para ocupação e ao servir determinada refeição ou bebida são basicamente os mesmos para todos os hóspedes; embora esses procedimentos operacionais ou rotinas possam ser ligeiramente padronizados, ao mesmo tempo criam desafios, porque é muito importante focar as necessidades de cada hóspede (TANKE, 2004).

Assim, a principal característica do setor hoteleiro é o papel desempenhado pelas pessoas e o contato direto e as interações entre a equipe de trabalho e os clientes. Segundo MULLINS (2004), "a eficiência total nas organizações hoteleiras não depende apenas dos produtos, dos serviços e das instalações oferecidas, mas muito mais das relações sociais, que se desenvolvem em cada estabelecimento". Assim, se, já no âmbito geral da vida cotidiana, a hotelaria é espaço de uma hospitalidade encenada, (GOTMAN, 2008; CAMARGO, 2009), essa encenação deve ter por objetivo a chamada hospitalidade (LASHLEY e MORRISON, 2003), a capacidade de ser hospitaleiro. Nos diferentes espaços da vida cotidiana, essa hospitalidade é fator essencial para o pleno desenvolvimento da sociabilidade, e, com muito mais razão, isto se aplica ao setor hoteleiro Colocar, pois, um estagiário numa recepção de hotel sem o devido treinamento e sem o conhecimento da cultura da empresa é, no mínimo, uma temeridade.

Entre parênteses: a maioria dos hotéis executivos de serviços completos possui três áreas funcionais principais que podem apresentar algumas variações de acordo com os portes dos mesmos, razão pela qual são aqui consideradas como campos privilegiados de atuação profissional e de estágio de alunos: hospedagem (ISMAIL, 2004; ASSIS, 2009; BASSOTO, 2008), atividade central do hotel, cuja estruturação depende das dimensões do mesmo, incluindo recepção, portaria social, auditoria noturna, setor de reservas, governança e segurança; alimentos e bebidas (FREUND, 2005), incluindo o bar, a cozinha e o restaurante, a 
mais complexa em toda a estrutura hoteleira, razão pela qual, muitos hotéis a terceirizam; e eventos (PRONETTHO, 2010) - área intrinsecamente, relacionada a alimentos e bebidas e hospedagem.

Esses hotéis, como qualquer outra empresa, são o núcleo de uma cultura organizacional diferenciada (SAINSAULIER, 2002) ${ }^{3}$ na qual todo empregado deve ser introduzido. E os estagiários?

\section{Experiência Profissional Anterior ao Estágio}

Não há exigência de experiência profissional anterior ao estágio, o que seria de qualquer forma absurdo, já que o estágio é exatamente a esperada primeira oportunidade profissional. Esta foi a resposta da maioria dos alunos entrevistados. Estes mencionaram que o interesse demonstrado pelo aluno e percebido pelo selecionador, bem como o interesse em aprender continuamente demonstrado desde o início, contribuiu mais do que qualquer experiência anterior. Como afirmou um aluno:

Para a minha contratação como estagiária de governança não foi exigida experiência anterior. A falta de experiência em hotelaria, especificamente nesse setor, não foi determinante para a contratação dos estagiários, pois eles (os recrutadores) demonstravam no ato da contratação, que queriam estudantes com vontade de trabalhar e aprender.

Entretanto a experiência profissional anterior obtida em hotelaria ou em outras áreas afins, de certo modo, contribuiu como diferencial competitivo do aluno como candidato ao cargo de estagiário em hotelaria. Durante a entrevista realizada com um aluno, o mesmo mencionou o seguinte sobre sua contratação:

Não foi exigida experiência anterior na função quando estagiei na área de reservas, eu não tinha nenhuma experiência na área de operação hoteleira, estava no primeiro semestre da faculdade. No meu segundo "estágio" na área

3 De 1972 a 2002, o sociólogo francês Renaud Sainsaulieu (2002) estudou as relações no trabalho e nas empresas e organizações como produtoras de um ambiente gerador de cultura, modelando comportamentos e atitudes e produzindo uma identidade social e profissional. Segundo ele, tal cultura é diferente segundo os diferentes escalões, ao longo de um eixo que tem, numa ponta, o alheamento típico dos trabalhadores não especializados, à uma sociabilidade entre os operários qualificados, que tem como limite a competição pela ascensão na empresa. 
de eventos, foi necessária experiência anterior, pois a vaga era de mais confiança e seria necessário conhecer a conduta do profissional. Mas não foi exigida experiência anterior no setor de eventos. Eu tinha experiência apenas na área de hospedagem.

De acordo com outro aluno entrevistado não se exigiu experiência anterior em hotelaria, porém o intercâmbio para outro país realizado anteriormente abriu-lhe portas. Ele apenas tinha uma noção bem pequena da área. O estágio o surpreendeu ao proporcionar-lhe um autoconhecimento e mostrar-lhe o que ele realmente gostaria de fazer.

Como se viu na metodologia, além do veio principal dos depoimentos de ex-estagiários, contou-se, também, ainda que como ilustração, com os depoimentos de gestores. Assim como a maioria dos alunos entrevistados, os dois gestores ouvidos mencionaram não ser relevante a experiência profissional anterior ao estágio para a contratação de um estagiário de hotelaria para os hotéis. Segundo um deles:

$\mathrm{Na}$ verdade entendemos que o estágio é necessário para que os alunos tenham em mente o que cada função ou departamento exige e com isso poderá tomar a decisão escolhendo o que mais lhe é interessante e que poderá fazê-lo feliz. Há sempre um diálogo com o aluno e se este tiver interesse em um único setor ou em alguns de preferência, estaremos contemplando-o para que ele possa escolher o seu futuro.

\section{Amplitude da Função do Estagiário de Hotelaria dentro do Hotel}

Em resposta à questão relacionada à categoria de amplitude da função de estagiário de hotelaria dentro do hotel e ao indicador de outras funções além de hospedagem e alimentos e bebidas, a maioria dos alunos mencionou que os hotéis também contratam estagiários de hotelaria para outras áreas, como para a área de eventos. Entretanto, dependendo da rede hoteleira, os hotéis deixam de contratar estagiários de hotelaria para as áreas como Recursos Humanos e Controladoria que, a seu ver, requerem estudantes de Psicologia e Administração.

De acordo com um dos alunos entrevistados:

No hotel em que estagiei, as áreas em que admitem são as principais, como Governança, Recepção, Alimentos e Bebidas (Cozinha e Salão do Restaurante) e também acontecem contratações para estagiários de Guest Relations (Telefonia). Nas demais áreas, como eventos, vendas, marketing, 
administrativo/financeiro, recursos humanos entre outras, não presenciei a contratação de estagiários, apenas de efetivos, com ou sem experiência.

Esse depoimento deve dar o que pensar aos educadores e alunos. Entende-se que não se pode jogar no colo de um estudante a responsabilidade por áreas tão sensíveis à clientela hoteleira. Não se entende, contudo, que o estagiário não possa ao menos acompanhar e, sob orientação de profissionais mais experientes, aprender um pouco dessas áreas. Mas isso parece acontecer apenas nas redes hoteleiras ou nos hotéis mais sofisticados. Segundo outro aluno entrevistado:

O hotel que eu estagiei/trabalhei admite estagiários de hotelaria em todas as áreas exceto na cozinha. São admitidos estagiários para as áreas operacionais como: recepção, reservas, atendimento no bar e restaurante, eventos, administrativo, etc. $\mathrm{O}[\ldots]$ (hotel) não tem um departamento de Marketing, $\mathrm{RH}$ ou Vendas por ser um hotel econômico. Os próprios gerentes fazem as negociações com fornecedores bem como as admissões e entrevistas de funcionários.

De acordo com outro aluno entrevistado:

Lá eles pegam estagiários para RH, Financeiro, Vendas, Governança, Eventos, Reservas, Mensageiros (Recepção) e Marketing. Nunca vi estagiário em Alimentos e Bebidas. Já vi menor aprendiz em A\&B (Alimentos e Bebidas) e em infra-estrutura. Na recepção também nunca vi. Para esse setor eles querem contratar pessoas com tempo livre, que não estejam estudando.

Assim como os alunos entrevistados, os gestores entrevistados também afirmaram que há estagiários contratados nos hotéis para praticamente todos os setores. Entretanto alguns destes setores são mais difíceis de proporcionar continuidade ou oportunidade de crescimento aos estagiários. Segundo um dos gestores entrevistados:

Atualmente temos estagiários nos departamentos de vendas, eventos, governança e recursos humanos. Mas não há restrição nenhuma para atuar em qualquer área do hotel. As chefias dos departamentos passam as demandas, sem passar as informações que não julgar necessárias ou as sigilosas do empreendimento.

E de acordo com outro gestor entrevistado:

Admitem-se estagiários para todos os setores, contudo tem que saber que alguns setores são mais difíceis de ter continuidade ou de oportunidade de 
crescimento. Caso de controladoria que se opta por profissionais de economia ou contábeis, e também, (o caso de) recursos humanos com direcionamento para formados em psicologia ou administração.

Desses depoimentos depreende-se que a desenvoltura no trato entre hoteleiros e estagiários é prejudicada por objetivos inconfessos de ambos os lados. Não se poderia dizer que o aproveitamento de estagiários tem menos a ver com a formação e mais com o aproveitamento de mão de obra barata?

\section{Programas de Treinamento nos Hotéis}

Em resposta as questões relacionadas à categoria de programas de treinamento nos hotéis e aos indicadores de programas de treinamento para os funcionários e programas de treinamento específicos para os estagiários, a maioria dos alunos mencionou não haver nenhum programa de treinamento específico para estagiários, apenas para os funcionários nos hotéis. Mas os estagiários de hotelaria até podem participar de alguns destes treinamentos.

De acordo com um dos alunos entrevistados o mesmo mencionou o seguinte em relação à existência de treinamentos específicos para estagiários:

Basicamente os estagiários participavam do mesmo treinamento que outros funcionários, o que tínhamos também na [...] (rede hoteleira), era uma reunião em todo final de mês, que também funcionava como treinamento, porque fazíamos uma espécie de boas práticas com o que estava acontecendo em outros hotéis da rede, e discutíamos sobre o desempenho da equipe, porém essa reunião era feita entre as equipes de cada departamento.

Segundo outro aluno entrevistado, no hotel onde o mesmo estagiou, havia um programa de treinamento criado pela diretoria de hospitalidade, direcionado aos funcionários do hotel como um todo, tanto estagiários como efetivos:

No [...] há um programa que se chama "Sou você por um dia". Quem quiser participar coloca o nome em uma lista e depois há um sorteio para qual setor você vai treinar. Se gostar, você pode avisar o RH, e caso surgir uma vaga para o setor, você pode se candidatar. Esse programa ocorreu no final do ano passado, e foi a (...) Gerente Geral do hotel que criou. E foi a primeira vez com os colaboradores, porque antes esse programa só acontecia com as 
chefias. Isso ocorre duas vezes ao ano e é bem legal porque dá oportunidade de conhecer outros setores.

De acordo com outro aluno entrevistado, os treinamentos informais foram mais comuns que os treinamentos formais, e os mesmos foram direcionados tanto para os funcionários quanto para os estagiários do hotel. O mesmo aluno entrevistado mencionou que até ocorriam treinamentos mais específicos quando entravam estagiários para o mesmo turno (matutino, vespertino ou noturno), mas se tratavam mais de orientações típicas do estágio, que treinamentos propriamente ditos:

Meu treinamento foi aprender com o dia-a-dia, e com a ajuda da líder da recepção. Não houve um treinamento (formal). O único que eu fiz, foi quando mudou o sistema de internet para hóspedes. [...] um treinamento sobre a utilização da nova forma de internet para os hóspedes. Ele foi realizado no próprio hotel, durante o horário de trabalho, teve duração de duas horas e foi ministrado pelos técnicos da empresa da internet. [...], quando entravam vários estagiários no mesmo período ocorriam treinamentos e integrações específicas.

Naturalmente, os gestores tendem a sublinhar o que existe, em detrimento do que não existe como operações de T\&D. Assim como alguns dos alunos entrevistados, os gestores mencionaram treinamentos padronizados das redes hoteleiras aplicados aos funcionários nos hotéis. Entretanto, alguns outros treinamentos direcionados aos estagiários foram criados pelos próprios hotéis. Segundo um dos gestores entrevistados:

Fazemos um programa de seis meses rotativo, onde o aluno acompanha todos os setores do hotel. Também temos os focados num único setor (ex: A\&B - Alimentos e Bebidas - nesse caso restringimos o estágio por todos os setores, nos concentrando nas áreas como cozinha, restaurante, compras e eventos). O estagiário é acompanhado por um chefe de departamento, mas sempre com um padrinho que o assiste.

E de acordo com outro gestor entrevistado:

Existem treinamentos técnicos para todas as funções, com formulários padrões. Todos estes arquivos são disponíveis no webdesk do [...] (intranet do hotel). A remodelação só poderá ser feita se for por alguma particularidade da unidade. Por exemplo, no treinamento de reservas existe o 
procedimento de efetuar reserva Utell, mas nem todas as unidades (da rede hoteleira) usam este canal, então excluem este [...] (treinamento).

\section{Tipologias de Treinamento Aplicáveis ao Estágio}

Alguns alunos mencionaram não ter participado nem mesmo de um treinamento de integração. A maioria deles mencionou ter realizado apenas um tour pelas dependências do hotel para conhecer e entender o seu funcionamento em sua totalidade. Um dos alunos entrevistados descreveu como ocorreu o tour realizado nos primeiros dias de estágio no hotel:

Na primeira semana eles fazem com o pessoal um acompanhamento, tanto com os estagiários quanto com os funcionários, que entram para conhecer todos os departamentos. A pessoa responsável pelo RH me levou para conhecer os demais departamentos do hotel, assim pude conhecer melhor a equipe. Também houve festa de funcionários, e lá os novos foram apresentados aos demais.

E segundo outro aluno entrevistado:

O treinamento de integração foi realizado em dois dias, onde conhecemos a empresa, o seu produto e a sua maneira de atuar no mercado. Este treinamento foi realizado em um dos hotéis da rede. O treinamento era ministrado por funcionários da própria rede, da área de $\mathrm{RH}$, usava-se data show, era dinâmico, principalmente, o treinamento de "DIA DE HÓPEDE", que foi bem divertido e interessante. O treinamento de integração acontecia, preferencialmente, antes da entrada de um novo funcionário, mas era sempre uma vez ao mês, por isso acontecia de um funcionário fazer depois de algumas semanas, dependia da data da integração. E o de "DIA DE HÓSPEDE", era feito quase que mensalmente, mas tinha algumas variações.

Como era de se esperar, os gestores entrevistados mencionaram existir integração, tanto para os funcionários quanto para os estagiários, em ambos os hotéis. Segundo um dos gestores entrevistados:

Todos os colaboradores, estagiários ou não, ao entrarem no hotel passam pelo treinamento inicial, com o objetivo de integração e orientação da cultura e filosofia da rede, e sua identidade organizacional. Este treinamento tem a duração de oito horas, é expositivo e com dinâmicas - sempre bem participativo. Como obrigatoriamente deve ser aplicado mensalmente, pelo $\mathrm{RH}$, nos meses que não ocorrem admissões, é aplicado para uma turma de reciclagem - formada por colaboradores com mais de três anos de empresa. 
Em relação às demais tipologias de treinamento, o panorama é ainda mais deserto, como já foi mencionado acima. Um dos alunos entrevistados mencionou o seguinte sobre alguns dos treinamentos recebidos durante o estágio:

Fui convocada apenas para treinamentos e palestras institucionais no decorrer do meu estágio, como o treinamento para brigada de incêndio, que ocorreu no próprio hotel, $[\ldots]$, quem o ministrou foi um bombeiro que tem parceria com o hotel há muitos anos. [...]. E a palestra da CIPA, esclarecendo a segurança do trabalhador, que também aconteceu no hotel [...], e foi ministrado por uma empresa de segurança no qual não me recordo do nome $[\ldots]$.

E segundo outro aluno entrevistado:

No decorrer desses onze meses, participei de um treinamento de manutenção de alimentos, onde todos os funcionários participaram e também de um treinamento voltado para a filosofia do [...] (hotel) de Alma Brasileira, onde uma vez por mês havia um encontro entre alguns funcionários de cada hotel da rede e nós tínhamos uma espécie de dia de hóspede, para conhecer todos os atributos de e características do produto oferecido pelo hotel.

Ao entrevistar os gestores dos hotéis, os mesmos afirmaram a aplicação de outros treinamentos aos estagiários nos hotéis no decorrer do estágio, entretanto com uma freqüência diferenciada em relação à aplicação destes mesmos treinamentos aos funcionários. Segundo um dos gestores entrevistados:

Para o [...] sim, mas não é hábito dos demais (hotéis). Entendemos que se abordados por um cliente (os estagiários) devem responder as necessidades destes. Cada hotel tem a liberdade de incluir os estagiários nos treinamentos que fazem nas unidades. Exemplo: Produtos de limpeza com a (Johnson) Diversey - posso incluir estagiários, mas fica a critério de cada hotel.

E de acordo com outro gestor entrevistado, "os estagiários participam de todos os cronogramas de treinamento da [...] (rede hoteleira), igualmente ao dos colaboradores efetivos." 


\section{Interesse do Aluno-estagiário pelo Estágio}

Em relação às questões envolvendo a categoria de interesse do aluno-estagiário pelo estágio e aos indicadores de satisfação/motivação, insatisfação/desmotivação pelo estágio, a maioria dos alunos entrevistados mostrou-se bastante interessada de início, entretanto ao longo do estágio, alguns destes alunos foram se desmotivando devido às más impressões que ficaram dos hotéis nos quais estagiaram. Percebe-se que a ausência de participação em treinamentos ao longo do estágio, foi um dos motivos, senão o motivo principal, contribuinte para a desmotivação dos estagiários. Mesmo assim, a maioria dos alunos entrevistados mostrou-se satisfeita/motivada ao mencionar a importância do estágio como primeira experiência profissional em hotelaria e como meio de ingresso no mercado de trabalho.

Um dos alunos entrevistados mencionou o seguinte sobre o estágio realizado e sobre os treinamentos recebidos:

A importância dos treinamentos recebidos no decorrer do estágio para mim é de crescimento profissional, de amadurecimento, de conhecimento e de importante trabalho de equipe, de treinamentos que nos ensinam a trabalhar, a respeitar os colegas de trabalho com diferentes opiniões, saber ouvir, ter atitudes relevantes e fazer cada dia melhor seu trabalho e o mais importante, ser feliz no que faz.

De acordo com outro aluno entrevistado, o estágio realizado foi avaliado como plenamente satisfatório:

Os treinamentos foram super interessantes e construtivos para mim, além de ajudarem a fugir da rotina do trabalho. Gostei do estágio, acho que foi importante apesar de ser muito operacional o que tornava o trabalho cansativo. Gostei principalmente da equipe que trabalhei que foi extraordinária e tornou o estágio sem dúvida excepcional.

Segundo outro aluno entrevistado, que avaliou o estágio positivamente, o treinamento se mostrou essencial logo de imediato ao ingressar como estagiário no hotel, devido à ausência de experiência profissional anterior:

Acho que no [...] (hotel) fez falta (o treinamento) no começo, pois eu não tinha nenhuma experiência, mas o dia-a-dia foi uma forma muito boa de 
aprender. Foi muito bom, pois o treinamento além de permitir conhecer o funcionamento, também auxilia nos momentos que surgem dúvidas durante o trabalho.

Alguns alunos entrevistados demonstraram insatisfação em relação ao estágio realizado nos hotéis, tendo mencionado que os hotéis fizeram pouco caso deles, ou seja, demonstraram indiferença em relação aos mesmos nessas organizações hoteleiras. Possivelmente, esses alunos se sentiram como uma mão de obra barata por não terem recebido merecida atenção e orientação por parte dos gestores dos hotéis. Um dos alunos entrevistados mencionou ter sido jogado na "jaula dos leões", sem ao menos, ter sido apresentado, como devido, às pessoas as quais trabalharia diariamente. $\mathrm{O}$ mesmo aluno também relatou não ter recebido nenhum treinamento durante sua permanência no hotel como estagiário. Outro aluno entrevistado, também demonstrou insatisfação ao mencionar que a rede hoteleira para qual o mesmo estagiou, pecou muito em relação a ele, tendo desconsiderado por completo seus préstimos na época em que o aluno realizou o estágio no hotel.

De acordo com outro aluno entrevistado, a falta de treinamento contribuiu para sua desmotivação em relação ao estágio:

No período que fiquei estagiando não participei de nenhum treinamento, aliás, na época achei muito ruim, pois faltava motivação para os estagiários e muitos acabavam saindo antes mesmo de completar o estágio. Isso aconteceu comigo por exemplo. Porém os funcionários tinham treinamento periodicamente. [...]. Quanto ao estágio, foi ótimo, pois a equipe do restaurante é bem sólida, os funcionários têm em média seis anos de casa, são acolhedores, dividem informação e valorizam seus trabalhos. Apesar do pouco tempo de experiência no estágio, aprendi muito do sistema operacional do respectivo departamento. Minha avaliação quanto ao estágio é que eu poderia ter ficado um pouco mais para valer melhor a experiência.

Um dos gestores entrevistados mencionou o seguinte sobre a importância do treinamento como forma de motivação e incentivo para os funcionários no hotel:

Os treinamentos têm grande importância na [...] (rede hoteleira). A média de horas de treinamento por colaborador mês é considerada um dos indicadores na avaliação dos resultados da unidade. Para a [...] (rede hoteleira) são os treinamentos que garantem a padronização do serviço, além dos 
treinamentos serem responsáveis pelo auxilio no incentivo à motivação dos colaboradores.

\title{
9. Considerações Finais
}

Estruturas físicas, decoração e tecnologia são fáceis de ser implantadas, porém o capital humano que ainda continua sendo o principal diferencial do mercado hoteleiro, não é tão fácil assim de se viabilizar. Segundo Márcio Moraes, diretor da Quem Indica Consultoria e Consultor Sênior em planejamento de carreira para profissionais do mercado hoteleiro: "Para que de fato ocorra uma expansão de toda a oferta hoteleira no país se faz necessária a qualificação das bases de gerência, operacional e administrativa"4.

Cursos técnicos e profissionalizantes de curta duração, não necessariamente trarão resultados efetivos e do alcance de todos os campos de formação hoteleira, pois ainda segundo Márcio Moraes, existe uma grande preocupação em voga:

\begin{abstract}
A falta de sintonia entre o mercado de trabalho e as instituições de ensino, que pouco dialogam. Para citar pequenos exemplos, as grades curriculares das universidades são incompatíveis com as necessidades do mercado e poucas empresas conhecem realmente a verdadeira importância dos estagiários.
\end{abstract}

$\mathrm{Na}$ verdade, o problema da falta de mão de obra qualificada é do mercado como um todo. Se, de um lado, o mercado carece de profissionais qualificados, por outro lado, o setor acadêmico percebe a diminuição desenfreada da demanda por cursos, quem sabe porque não se sinta o seu potencial formador efetivo (e o estágio tem grande responsabilidade nesse processo), quem sabe por que surgem cursos técnicos que proporcionam ascensão profissional, quem sabe ainda pelo mito do simplesmente aprender em serviço. Isso não é verdade, ao menos como regra, pois como diz Aguiar:

Tendo em vista que o treinamento age como elemento que altera comportamentos, proporciona habilidades e desenvolve competências, nota-

\footnotetext{
${ }^{4}$ Diretor da Quem Indica Consultoria e Consultor Sênior em planejamento de carreira para profissionais do mercado hoteleiro. Artigo divulgado no sitio Hôtelier News, em 2010. Disponível em: $<$ http://www.hoteliernews.com.br/hoteliernews/hn.site.4/Imprimir.aspx?Noticia=54874\&Midia=1>. Acessado em: 04 mai. .2011.
} 
se a sua importância nos hotéis, pois o sucesso destas organizações depende diretamente da boa relação entre funcionários e hóspedes (2008, p.9).

Este estudo justifica-se, portanto, pelo fato de que poucas empresas reconhecem a real e verdadeira importância dos estagiários, e no caso da hotelaria, poucos hotéis reconhecem que os estagiários de hotelaria, se bem treinados, poderiam se tornar profissionais valiosos às empresas. Assim sendo, a captação de estagiários de hotelaria, no mercado hoteleiro, vem se tornando um modo "inteligente" de admissão de jovens com formação acadêmica especializada, ainda que com pouca ou nenhuma experiência profissional. As empresas hoteleiras, na maioria das vezes, não dão merecida atenção ao processo de treinamento e desenvolvimento dos estagiários, deste modo, não desenvolvem neles os conhecimentos, habilidades e atitudes indispensáveis a boa condução do estágio curricular obrigatório e da carreira profissional.

Como os estagiários percebem os processos de treinamento dirigidos a si mesmos, como estagiários, e na comparação com os processos direcionados aos demais funcionários nas organizações hoteleiras? E mais, será que os gestores de hotéis tão queixosos da baixa qualificação ou qualificação insuficiente dos profissionais do mercado de trabalho, dão atenção merecida aos estagiários de hotelaria? E ainda, será que os estagiários de hotelaria se sentem explorados pelos hotéis?

A falta de representatividade da amostra impede a extrapolação das conclusões quanto ao universo dos estagiários, inclusive no espaço de observação aqui delimitado, a cidade de São Paulo. Em consequência, os comentários que se seguem devem ser considerados menos como conclusões assertivas e mais como hipóteses a serem validadas em estudos mais.

Percebeu-se que a maioria dos hotéis não dispõe de uma gama de programas de treinamento para os funcionários como seria de se esperar, sendo aplicados, no máximo, treinamentos de integração e outros poucos treinamentos direcionados aos funcionários de acordo com as necessidades e especificidades de cada departamento ou setor nos hotéis. Os treinamentos mais complexos são direcionados aos gestores, que inclusive, recebem até incentivo para realizarem pós-graduação de especialização ou de MBA (Master Business Administration). A Educação Corporativa, através de Universidades Corporativas, tem-se mostrado uma tipologia 
de treinamento restritiva e ultrapassada por envolver única e exclusivamente o ambiente interno à organização, impedindo a plena difusão de idéias e a troca de conhecimentos e experiências entre profissionais de outras organizações hoteleiras, sendo mais difundida nos níveis operacional e tático das organizações.

Percebeu-se também que, apesar das distintas categorias classificatórias dos hotéis, não há praticamente nenhuma distinção em relação aos processos e às práticas de treinamentos nos hotéis de alta, média e baixa qualificação. E que nenhuma rede hoteleira mostrou-se preocupada em realizar treinamentos específicos para os estagiários, por estes constituírem minoria e, possivelmente, por permanecerem um curto período de tempo nos hotéis.

É importante notar que o objetivo aqui não é um diagnóstico do T\&D nos hotéis de São Paulo em si mesmos, embora a observação acima já induza a um esboço do problema, mas sim da perspectiva dos estagiários e do sentimento de exclusão da cultura organizacional por eles experimentado. Quem sabe esse sentimento de exclusão seja ao mesmo tempo causa e efeito das suas percepções em relação a essa área nos hotéis?

Infelizmente esta pesquisa não pode ir além dos seus objetivos, mas não restam dúvidas de que essa pouca atenção conferida ao treinamento de estagiários pelos gestores de hotéis deve algo a uma ainda má compreensão na realidade brasileira do custo/benefício da iniciativa.

Esta pesquisa pretende ser útil às universidades para o aprimoramento dos estágios curriculares nos cursos de hotelaria para mostrar as dificuldades encontradas pelos alunos. Estes, na maioria, impressionam-se ao perceber que tudo aquilo aprendido na sala de aula mostra-se ora aquém ora além do que realmente acontece no mercado de trabalho, pois o aluno aprende como tudo deveria ser e não como é na realidade com que ele se defronta pela primeira vez no momento do estágio.

Não há dúvidas de que algo de errado se passa com os estágios e isso talvez se deva mais à concepção do próprio MEC quanto à atividade. O aluno não deve apenas ser "condenado" ao estágio como pré-requisito para obtenção do diploma e talvez este devesse incorporar uma nova concepção didática, mais próxima à dos "trainees" que a de "curiosos" que os hotéis são obrigados a aceitar. 
A título de resumo da discussão dos resultados, deve-se destacar o mal estar de alunos com relação à atividade de estágio. Se estes constituem a maioria, como os depoimentos colhidos sugerem, cabe, quem sabe, a uma pesquisa aprofundada (e muito difícil) desvelar. O mal estar experimentado por esses alunos aparece claramente nos depoimentos.

De início, extremamente motivados, ansiosos por conhecer e desenvolver uma prática profissional, por terem uma profissão agradável, marcada pelo contato com os clientes e cheia de surpresas e de acontecimentos agradáveis, não raro alguns se frustram, ao final. Talvez por falta de preparação e pelo glamour que envolve a atividade hoteleira, vêem-se decepcionados com o que encontram. No mais das vezes, tratados como mão de obra barata, submetidos a tarefas subalternas para as quais são designados nunca por suas qualidades técnicas e mais pelo "oi-você-aí", o desgaste e a decepção são naturais.

Nem é de se espantar que os alunos às vezes abandonem o estágio e, até mesmo, o curso, exatamente pela faceta mostrada no hotel. Aliás, nestas considerações finais, não se pode deixar de colocar ao menos como uma hipótese de estudo a observação aleatória que mostra a frustração com o estágio como uma das principais causas da evasão de alunos do curso de Hotelaria.

\section{Referências}

AGUIAR, I. L. Treinamento e desenvolvimento em organizações de serviços hoteleiros. 2008. Trabalho de conclusão de curso (Bacharelado em Engenharia de Produção e Sistemas) - Universidade do Estado de Santa Catarina, Joinville, 2008. Disponível em: $<$ http://www.producao.joinville.udesc.br/tgeps/2008-01/2008_1_tcc10.pdf $>$. Acesso em: 19 jul. 2010.

ASSIS, F. A. A. Práticas de gestão de pessoas no setor hoteleiro de Juiz de Fora- MG. 2009. Dissertação (Especialização em Gestão de Negócios em Turismo) - Universidade de Brasília, Brasília, 2009. Disponível em: <http://bdm.bce.unb.br/bitstream/10483/1009/1/2009_FredericoAzevedo AlvimAssis.pdf $>$. Acesso em: 11 set. 2010.

BASSOTO, R. N. O processo de treinamento, desenvolvimento e educação: um estudo junto aos funcionários de recepção de hotéis de rede em Porto Alegre. 2008. Trabalho de conclusão de curso (Bacharelado em Administração) - Universidade Federal do Rio Grande do Sul, Porto Alegre, 2008. Disponível em: <http://www.lume.ufrgs.br/bitstream/handle/10183/18136/000686823.pdf?sequence $=1>$. Acesso em: 11 set. 2010 .

BISSOLI, M. A. M. A. Estágio em turismo e hotelaria. São Paulo: Aleph, 2003.

BOHLANDER, SNELL e SHERMAN. Administração de recursos humanos. São Paulo: Pioneira Thomson Learning, 2005. 
BOOG, G.; BOOG, M. Manual de treinamento e desenvolvimento: gestão e estratégias. São Paulo: Pearson Pretice Hall, 2006.

CASTELLI, G. Gestão Hoteleira. São Paulo: Saraiva, 2006.

CAMARGO, L. O. L. A pesquisa em hospitalidade. Ver. Hospitalidade. Universidade Anhembi Morumbi, Ano V, Número 2 - Dezembro 2008.

CHIAVENATO, I. Gestão de pessoas: o novo papel dos recursos humanos nas organizações. Rio de Janeiro: Elsevier/Campus, 2010.

CLARKE, A.; CHEN, W. Hotelaria: fundamentos teóricos e gestão. Rio de Janeiro: Elsevier/Campus, 2008.

ESPINDULA e outros. Análise sobre a contribuição dos estágios na vida acadêmica e profissional. Disponível em: <http://www.congressousp.fipecafi.org/artigos72007/164.pdf>. Acesso em: 03.abr.2011.

FREUND, F. T. Alimentos e bebidas: uma visão gerencial. Rio de Janeiro: Senac Nacional, 2005.

GOTMAN, A. A encenação da hospitalidade. In BUENO RAMOS \& CAMARGO. Consumo e cultura. Estilos de vida na contemporaneidade. São Paulo: Ed. SENAC, 2008, p.115-134.

HAYES, D. K.; NINEMEIER, Jack D. Gestão de operações hoteleiras. São Paulo: Pearson Prentice Hall, 2005.

ISMAIL, A. Hospedagem: front office e governança. São Paulo: Pioneira Thomson Learning, 2004.

JASINSKI, R.P. Estágio curricular: análise sobre a ótica da empresa, da universidade e do estagiário e possiveis pontos de melhoria. Curitiba: IARDES, IEL-PR, 199, p.65-80.

LASLEY E MORRISON (Orgs.) Em busca da hospitalidade: perspectivas para um mundo globalizado. São Paulo: Manole, 2003.

MULLINS, L. J. Gestão da hospitalidade e comportamento organizacional. Porto Alegre: Bookman, 2004.

OSORIO e SCHOENALI. Mitos, realidades e perspectivas do estágio. Curitiba: IARDES, IEL-PR, 199, p.1-18.

PRONETTHO (Programa Nacional de Eventos, Treinamentos em Turismo e Hotelaria). Modelo de hotelaria brasileiro: próximos de uma realidade? Publicado em 21 set. 2010. Disponível em: $<$ http://www.pronettho.com.br/v1/noticia.php?id=118>. Acesso em: 18 nov. 2010.

ROESCH, S. Projetos de estágio e de pesquisa em Administração. São Paulo, Atlas, 2005.

ROBBINS, S. P. Fundamentos do Comportamento Organizacional. São Paulo: Pearson Prentice Hall, 2009.

SAINSAULIER, R. Sociologia da empresa. São Paulo: DP\&A, 2007.

TANKE, M. L. Administração de recursos humanos em hospitalidade. São Paulo: Pioneira Thomson Learning, 2004.

Recebido em: 22/07/2011

Aprovado em: 12/02/2012 (1 ${ }^{\mathrm{a}}$ versão) $12 / 06 / 2012$ (2 $2^{\mathrm{a}}$ versão) 